\title{
Determining the Level of Accounting Conservatism through the Fuzzy Logic System
}

\author{
Josip Čičak \\ Faculty of Economics and Business, University of Rijeka, Rijeka, Croatia \\ Davor Vašiček \\ Faculty of Economics and Business, University of Rijeka, Rijeka, Croatia
}

\begin{abstract}
Background: Using a variety of alternative accounting policies brings about different effects on the stated business results and the value of the company. Objectives: The objective of this paper is to develop a fuzzy logic solution for determining bias in financial reports on low-activity financial markets, and to find a method applicable to unquoted entities. Methods/Approach: A fuzzy logic system was developed using data on Croatian companies, the MatLab software, and the Mamdani fuzzy inference method. Results: The paper provides the summary of results obtained using a fuzzy logic system, and they indicate that the model has relevant validity. Conclusions: The model can serve as a stimulus for more detailed studies of biased financial statements elements. The fuzzy logic model should be further tested on a larger sample of companies classified based on their activity and under different business conditions.
\end{abstract}

Keywords: accounting conservatism, aggressive accounting, fuzzy logic JEL classification: M41

Paper type: Research article

Received: Dec 05, 2018

Accepted: Feb 28, 2019

Citation: Čičak, J., Vašiček, D. (2019), "Determining the Level of Accounting Conservatism through the Fuzzy Logic System," Business Systems Research, Vol. 10 No. 1, pp. 88-101.

DOI: $10.2478 /$ bsrj-2019-0007

\section{Introduction}

Since the bias of elements of financial statements is determined by accounting policies and estimates, their choice is extremely important for business operations. Different approaches to estimating income, expenses, and costs, as well as assets, liabilities and capital, can lead to enormous discrepancies in the financial statements. Therefore, companies and regulators use the selected accounting policies and estimates in order to achieve certain goals (Solomons, 1986).

Although there are strict regulations regarding the application of accounting policies and estimates, the accounting processing implies a variety of situations in which it is possible, consciously or unconsciously, to deviate from principles, bases, arrangements, rules, and practices applied by the entity when preparing and 
presenting financial statements, thereby deviating from neutral financial statements. The deviation from neutral statements is often prevalent within the national accounting regulations, and the deviation has been the focus of many studies. However, even within national economies, which select certain accounting policies to reach a specific goal, the reported financial positions are the subject of bias in financial reporting.

The problem of determining bias in financial reporting arises from the lack of information. Namely, in order for investors and other stakeholders to estimate the deviation from neutral financial statements, they should have significantly more information than those contained in the reports for public disclosure purposes, particularly because the notes in financial statements only generally refer to the accounting standards according to which the elements of financial statements are valued. Almost all accounting standards contain alternative policies for recognition of the elements of financial statements, which, within the legal framework, produces different effects on the reported net assets, but also on the financial position.

In the last twenty years, numerous studies have been published in the area of bias in financial reporting, e.g., Gao et al. (2018), Lee et al. (2018) and Wang et al. (2018). Most of them analyze the positive influence of accounting conservatism on business operations and focus on recognizing accounting conservatism in financial statements.

Models for determining the level of conservatism have been developed, in addition to the previously known market-to-book ratio (MTB ratio), the first being the Basu regression (Basu, 1997). It was followed by models by Givoly et al. (2000), Penman et al. (2002), Ball et al. (2005), and Khan et al. (2009), while recently the standardized values of multiple models have very often been used simultaneously.

Although the aforementioned models were used in a large number of studies (André et al., 2015; Garcia Lara et al., 2016; Balakrishnan et al., 2016), none of the models were generally accepted as the absolute measure of bias in financial statements. In the last decade, authors have mostly used a combination of different measures of bias and drawn conclusions on the basis of standardized results. For example, Beatty et al. (2012) use the C_index which consists of the average or the standardized Basu (1997) measure, the negative accruals measure (Givoly et al., 2000) and the C_score measure (Khan et al., 2009). Values from different measures are standardized using the PCA (principal component analysis) method in the papers.

Recent research has indicated that fuzzy logic models could be useful in accounting (e.g., Lin et al., 2003; Giovanis, 2010, Qu et al., 2010), but fuzzy logic has not yet been applied in estimating accounting bias. Based on this research gap, the goal of this paper is to test the applicability of the fuzzy logic model for estimating accounting bias, in the low-activity financial markets, and to find a method applicable to unquoted entities. For that purpose, data on Croatian companies, extracted from the Amadeus database, are used and modelled using the Mamdani fuzzy inference method (Chai et al., 2009).

The paper is composed in the following manner. First, an introduction to the research was defined, and the research goal was set. Second, a literature review is provided, which is oriented to statistical modeling of bias in financial reporting, and fuzzy logic models in accounting research. The third section presents the methodology, the variables description, data explanation, and accounting bias modeling. The fourth section presents the results obtained through the correlation analysis and fuzzy logic modeling. Finally, conclusions and recommendations are provided in the fifth section of the paper. 


\section{Literature Review}

\section{Statistical modeling of bias in financial reporting}

The number of publications on bias in financial reporting is growing, most of them being related to the accounting conservatism issue. Ruch et al. (2015) gave an overall analysis of the literature in the field of accounting conservatism. Watts (2003a, 2003b) defines accounting conservatism "as the differential verifiability required for the recognition of economic gains versus losses."

Previously mentioned models are the basis for determining the level of accounting conservatism (Basu regression, 1997; Givoly et al., 2000; Penman et al., 2002; Ball et al., 2005; Khan et al., 2009), and are used in various application fields such as corporate governance, debt contracts, accounting standards, capital markets, accounting conservatism models testing etc.

Barker et al. (2015), André et al. (2015), Barker et al. (2013) discuss accounting conservatism in International Financial Reporting Standards. The influence on capital markets in the United Kingdom (UK) and the United States of America (USA) has been investigated by Huijgen et al. (2005), and the finding was that companies which are listed on both markets have a higher level of accounting conservatism. Kim et al. (2013) investigated the influence of conservatism on the success of the stock issue on the capital market. The influence of conservatism on debt markets is covered by Nikolaev (2010), Zhang (2008) \& Ahmed et al. (2002). Other authors researched the impact of accounting conservatism on corporate governance (Ahmed et al., 2013; García Lara et al., 2009; Ahmed et al., 2007).

Basu's (1997) operationalization of bias in accounting reporting focuses on the implication that earnings will reflect 'bad news' more quickly than 'good news,' which is known as the asymmetric timeliness of earnings. The Basu (1997) regression is the most commonly used method for determining bias, but there are numerous critics of this method, such as Dietrich et al. (2007) and Beaver et al. (2012). Dietrich et al. (2007) noticed econometric deficiencies in the Basu (1997) measure, including a sample-variance-ratio bias and a sample-truncation bias. Beaver ef al. (2012) noticed a simultaneity problem in the relationship between earnings and stock returns. However, Basu (1997) first notices and formulates a way to estimate the asymmetry of "news" recognition in company earnings, so this method has been a major breakthrough in this area.

The method devised by Givoly et al. (2000) is criticized because it is influenced by the base year. Later papers (Garcia Lara et al., 2009 and Ahmed et al., 2007) tried to standardize the base year on the basis of three years but did not remove the baseline bias.

Criticism of the method used by Penman et al. (2002) refers to the estimation of silent reserves. Their method does not examine bias in the given circumstances, i.e., bias in accordance with the regulation, but includes accounting policies that are not allowed or are partially permitted in the international accounting regulations to estimate silent reserves within the financial statements. In addition, Wang et al. (2009) state that research and development expenses are not explicitly stated in the financial statement, which is also confirmed by Čičak (2018) in his research in Croatia.

The model developed by Ball et al. (2005) is based on the Basu regression model. The difference is that Basu (1997) uses earnings per share as an indicator of "good" or "bad" news, and Ball et al. (2005) use net cash flows of business activities. The second difference is that in the Basu regression the dependent variable is the total earnings, 
while the Asymmetric Accrual to Cash-Flow (AACF) model by Ball et al. (2005) uses only the earnings of business activities as the dependent variable.

The C_score is a conservatism measure invented by Khan et al. (2009). This measure has been popular to researchers in the field of accounting conservatism in the last decade and was used in the papers of Beatty et al. (2011), Beatty et al. (2012), Ettredge et al. (2012), Kim et al. (2013), Tan (2013), André et al. (2015), Garcia Lara et al. (2016) and Balakrishnan et al. (2016). This measure investigates the relationship of the Basu measure with the specific characteristics of an enterprise. The specific characteristics of a particular company are the size, the MTB ratio and the indebtedness of the company.

Although the aforementioned models were used in a large number of studies and based on them, many conclusions that confirmed theoretical findings were made, none of the models were generally accepted as the absolute measure of bias in financial statements. In the last decade, the authors have mostly used a combination of different measures of bias, and they have drawn conclusions on the basis of standardized results.

\section{Fuzzy modeling in accounting research}

Fuzzy logic is a form of logic that extends on the widely used Boolean logic to allow the definition of unclear events (Lee, 1990). Unlike classical logic which requires a deep understanding of a system, exact equations, and precise numeric values, fuzzy logic incorporates an alternative way of thinking, which allows modeling complex systems using a higher level of abstraction originating from our knowledge and experience (Beskese et al., 2004). Spandagos et al. (2018) demonstrate the feasibility of fuzzy logic as a powerful method for combining quantitative economic and physical factors with qualitative behavioral concepts in a single mathematical framework.

Fuzzy logic has come into the field of economics in the last two decades. Díaz et al. (2012) describe the application of fuzzy logic in economics. Recently, fuzzy logic has been used in accounting research. Lin et al. (2003) use the fuzzy neural network model for the detection of fraud in financial reporting. Giovanis (2010) forecasts performance and the financial distress periods through the fuzzy logic. Qu et al. (2010) estimate the convergence level of national accounting standards (NAS) to International Financial Reporting Standards (IFRS) through the fuzzy logic. Thus their estimation, in other words, shows bias between NAS and IFRS. The research of Qu et al. (2010) and Lin et al. (2003) is important for this paper because it represents an estimation of bias in financial reporting through fuzzy logic.

Although there are examples of fuzzy logic-based research in accounting it was not applied with the aim of determining the level of accounting conservatism. Fuzzy logic has enormous potential in the field of determining bias in financial reporting because it allows for modeling complex systems using a higher level of abstraction originating from our knowledge and experience.

\section{Methodology}

\section{Research variables}

Six variables were used for fuzzy logic modeling, i.e., TAX, AMORT, LTIA, PROV, OCA and $O C L$, which mostly reflect the effects of applied accounting policies. Table one presents a description of the variables used in the analysis. 
manufacturing, which is represented by 300 companies. The construction industry is represented by 73 companies, transport operations by 63 enterprises, agriculture by 38 enterprises, information and communication by 41 enterprises, professional, scientific and technical activities by 40 enterprises, electricity, gas, steam and air conditioning supply by 30 enterprises, providing accommodation, food preparation and catering services by 30 companies, administrative and auxiliary services by 21 companies, water supply, sewage disposal, waste management and environmental remediation by 20 companies. The remaining 34 companies are divided into 7 industries, out of which 9 are registered for arts, entertainment, and recreation, six companies are registered for real estate business, five for health and social care services, five companies belong to the financial industry and the insurance industry, four companies to other services and four companies to mining, while education is represented by one company only.

The specificities of the industries have been investigated; the model was tested at the retail (370 companies) and the subcontracting industry (300 companies). Previous studies did not show differences in the values of the examined variables among the largest industries in the sample.

\section{Accounting bias modeling}

The determining of the level of bias in financial statements was conducted through the formed fuzzy logic system named "Ifuzzy4var". The "Ifuzzy4var" fuzzy logic system was formed on the basis of four input and one output variable.

In the MATLAB software, it is possible to form a Sugeno or a Mamdani fuzzy logic system. The Mamdani system was chosen because it is more appropriate for human logic and the research of this paper. The Mamdani fuzzy logic system was formed by specifying if-then rules. The rules were formulated on the basis of previously tested variables.

The description of the differences between the Mamdani and the Sugeno fuzzy logic system is available at https://www.mathworks.com. It is written that the Mamdani system is widely used in setting up intuitive models that are close to the human way of thinking, but according to Kaur et al. (2012), the Mamdani system has certain limitations regarding the mathematical formulation of logic. Unlike the Mamdani system, Sugeno Systems are more effective in the mathematical formulation of fuzzy logic, making them more applicable in control issues, especially in dynamic or nonlinear systems. Sugeno systems are used as optimization techniques and adaptation techniques. For example, customization techniques are used to standardize membership functions, so Sugeno Systems become an excellent tool for modeling various data.

The most significant difference, according to Kaur and Kaur (2012), between these systems is the way in which variables are generated. While Mamdani systems use defuzzification techniques for external variables, Sugeno systems use a weighted average for calculating the variable generating process. Interpretability and mathematical descriptiveness of the Mamdani system are smaller than of the Sugeno system, precisely because the outcomes of the rules in the system are not the rules and outcomes determined by the system, but the researcher. In addition to this, Sugno systems are faster because the weighted average encapsulates the time lost in the defibration process.

Another difference between these systems is that Mamdani systems have functions of output variables, whereas Sugeno systems do not have the function of output variables. Also, the Mamdani system, unlike the Sugeno system, is less flexible in the design of neural networks based on fuzzy logic. On the basis of the knowledge 
of both systems, it was concluded that Mamdani is the appropriate system to be used to uncover the logic and the knowledge of the problem involved in this research.

\section{Results}

\section{Correlation analysis}

The first step of the research was to collect data on the specified variables and to assess the neutral value of a particular variable. For all the variables, except the TAX variable, the mean value was determined by comparing the suitability of the statistical environment and the statistical median. For the TAX variable, the mean value was corrected by the income tax rate, which equaled 20\%, i.e., 0.2 in the observed period (2015) in Croatia. The correlation between the variables was calculated, which for this type of statistical analysis had to be extremely low (Table 2). The results of the correlation between the selected variables confirmed that suitable variables had been chosen.

Table 2

Correlation matrix

\begin{tabular}{lrrrrrr}
\hline & TAX & AMORT & \multicolumn{1}{l}{ LTIA } & PROV & OCA & \multicolumn{1}{l}{ OCL } \\
\hline TAX & 1.0000 & 0.0068 & 0.0562 & 0.0017 & -0.0289 & -0.0031 \\
AMORT & 0.0068 & 1.0000 & 0.0080 & 0.0008 & 0.0002 & -0.0099 \\
LTIA & 0.0562 & 0.0080 & 1.0000 & -0.0270 & 0.0922 & 0.0249 \\
PROV & 0.0017 & 0.0008 & -0.0270 & 1.0000 & 0.1312 & 0.0012 \\
OCA & -0.0289 & 0.0002 & 0.0922 & 0.1312 & 1.0000 & -0.0043 \\
OCL & -0.0031 & -0.0099 & 0.0249 & 0.0012 & -0.0043 & 1.0000 \\
\hline
\end{tabular}

Source: Authors' work

\section{Fuzzy logic modeling}

The determining of the level of bias in financial statements was conducted through the formed fuzzy logic system. The "1 fuzzy4var" fuzzy logic system was formed on the basis of four input and one output variable.

Figure 1

Fuzzy logic system 1 fuzzy4var

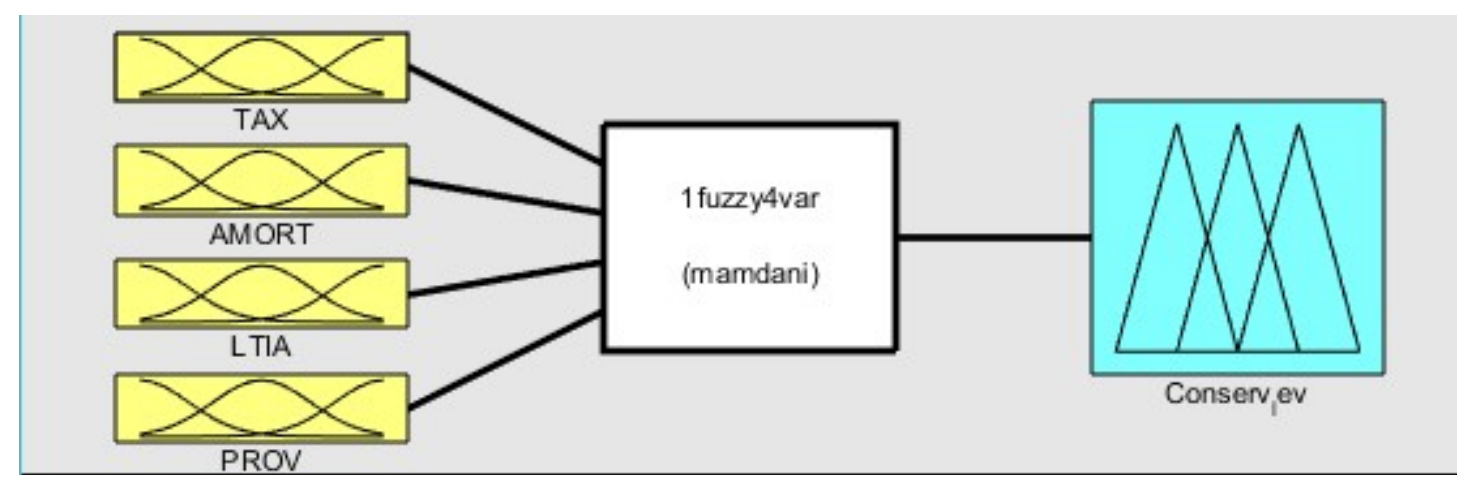

Source: Authors' work

In the construction of a fuzzy logic system, it is necessary to enter the functions of the input and the output variables and the system decision rules. The membership functions of the input and the output variables were introduced according to the previously analyzed data of 1,060 Croatian companies and are presented in Table 2. 
Table 2

Membership functions

\begin{tabular}{|c|c|c|c|}
\hline \multirow[b]{2}{*}{ Variables } & \multicolumn{3}{|l|}{ Variable values } \\
\hline & Low & Middle & High \\
\hline TAX & {$\left[\begin{array}{llll}-10.67 & -5.268 & 0.1292\end{array}\right]$} & {$\left[\begin{array}{llllll}-5.1 & 0 & 0.22\end{array}\right]$} & {$\left[\begin{array}{llll}0 & 0.22 & 10.5\end{array}\right]$} \\
\hline AMORT & {$\left[\begin{array}{llllll}-6 & 1.2 & -10 & 0.185\end{array}\right]$} & {$\left[\begin{array}{llll}-10 & 0.185 & 0.6\end{array}\right]$} & {$\left[\begin{array}{llllll}0.185 & 0.6 & 15.86\end{array}\right]$} \\
\hline LTIA & {$\left[\begin{array}{llll}0 & 0.0001 & 0.000186\end{array}\right]$} & $\begin{array}{l}{[0.0001} \\
0.037]\end{array}$ & {$\left[\begin{array}{lllll}0.000186 & 0.037 & 1\end{array}\right]$} \\
\hline PROV & {$\left[\begin{array}{lll}0 & 0.003 & 0.009\end{array}\right]$} & {$\left[\begin{array}{lllllll}0.003 & 0.009 & 0.2\end{array}\right]$} & {$\left[\begin{array}{llll}0.009 & 0.2 & 0.494\end{array}\right]$} \\
\hline & Aggressive & FAIR & Conservative \\
\hline Conservatism level & {$\left[\begin{array}{lll}-61 & -5 & 0.2\end{array}\right]$} & {$\left[\begin{array}{lll}-1 & 0.2 & 0.778\end{array}\right]$} & {$\left[\begin{array}{llll}0.2 & 0.778 & 15.555\end{array}\right]$} \\
\hline
\end{tabular}

Source: Authors' work

Table 2 shows the ranges of the input and the output variables. The input variables are assigned low, medium and high ranges, and the output variables can be in an aggressive, a fair or a conservative range. The variables architecture is also shown in Figure 2, showing the function of the input and the output variables in graphs. Figure 2 shows the functions of the input variables and the output variables graphically. By entering the values of the parameters shown in Table 2, the membership functions belonging to the individual variables are obtained.

Figure 2

Illustration of the fuzzy logic system architecture - 1 fuzzy4var
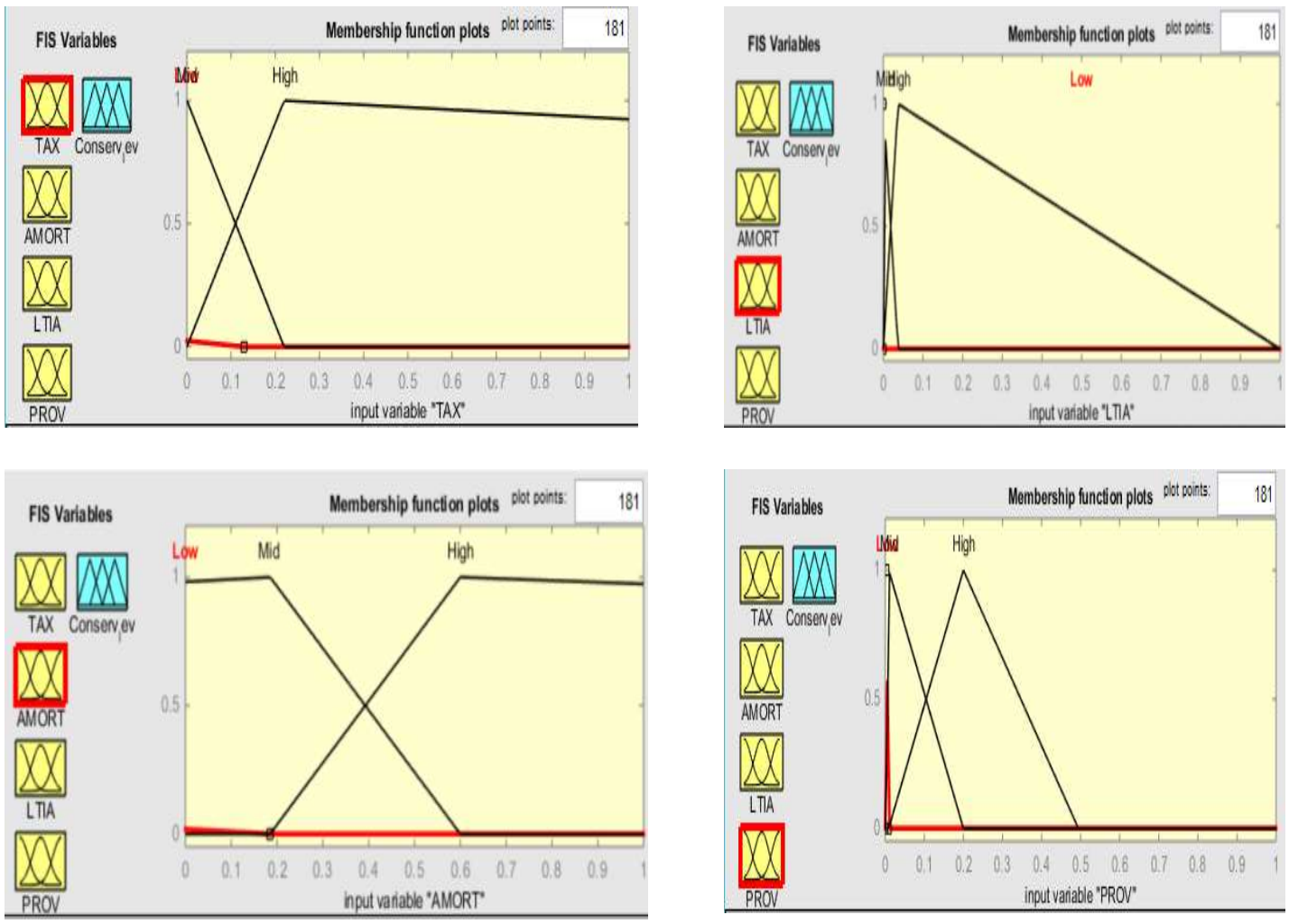

Source: Authors' work, using Matlab

When setting up the fuzzy logic system (Mamdani model), a researcher introduces if-then rules. The model is formed by entering rules, for example, if TAX is low, AMORT is low, LTIA is low, PROV is low, then the level of conservatism = aggressive. Since 
each of the four input variables can take three values (low, medium and high), it is necessary to form an 81 if-then rule, because the total number of possible combinations is $3^{4}=81$. The values of the output variable in a particular rule are determined by the combination of input variables. Therefore, the OCA and $\mathrm{OCL}$ variables were excluded from the formation of the fuzzy logic system. The inclusion of OCA and OCL variables would require 729 if-then rules because in case the system has six input variables that can take three values, there are 729 combinations $\left(3^{6}=\right.$ 729).

\section{Table 3}

IF-THEN rules used for fuzzy modeling

\begin{tabular}{|c|c|c|c|c|c|c|c|c|c|c|c|c|c|c|c|c|c|c|c|c|c|c|c|}
\hline \multirow{2}{*}{$\begin{array}{l}\# \\
1 .\end{array}$} & \multicolumn{5}{|c|}{ IF-THEN rule } & \multirow{2}{*}{$\begin{array}{l}\# \\
21 .\end{array}$} & \multicolumn{5}{|c|}{ IF-THEN rule } & \multirow{2}{*}{$\begin{array}{l}\# \\
42 .\end{array}$} & \multicolumn{5}{|c|}{ IF-THEN rule } & \multirow{2}{*}{$\begin{array}{l}\# \\
62 .\end{array}$} & \multicolumn{5}{|c|}{ IF-THEN rule } \\
\hline & 1 & 1 & 1 & 1 & 1 & & 1 & 3 & 1 & 3 & 3 & & 2 & 2 & 2 & 3 & 2 & & 3 & 1 & 3 & 2 & 2 \\
\hline 2. & 1 & 1 & 1 & 2 & 1 & 22. & 1 & 3 & 2 & 1 & 2 & 43. & 2 & 2 & 3 & 1 & 3 & 63. & 3 & 1 & 3 & 3 & 2 \\
\hline 3. & 1 & 1 & 1 & 3 & 3 & 23. & 1 & 3 & 2 & 2 & 2 & 44. & 2 & 2 & 3 & 2 & 2 & 64. & 3 & 2 & 1 & 1 & 3 \\
\hline 4. & 1 & 1 & 2 & 1 & 1 & 24. & 1 & 3 & 2 & 3 & 2 & 45. & 2 & 2 & 3 & 3 & 2 & 65. & 3 & 2 & 1 & 2 & 3 \\
\hline 5. & 1 & 1 & 2 & 2 & 1 & 25. & 1 & 3 & 3 & 1 & 2 & 46. & 2 & 3 & 1 & 1 & 3 & 66. & 3 & 2 & 1 & 3 & 3 \\
\hline 6. & 1 & 1 & 2 & 3 & 2 & 26. & 1 & 3 & 3 & 2 & 2 & 47. & 2 & 3 & 1 & 2 & 3 & 67. & 3 & 2 & 2 & 1 & 2 \\
\hline 7. & 1 & 1 & 3 & 1 & 1 & 27. & 1 & 3 & 3 & 3 & 2 & 48. & 2 & 3 & 1 & 3 & 3 & 68. & 3 & 2 & 2 & 2 & 2 \\
\hline 8. & 1 & 1 & 3 & 2 & 1 & 28. & 2 & 1 & 1 & 1 & 2 & 49. & 2 & 3 & 2 & 1 & 2 & 69. & 3 & 2 & 2 & 3 & 3 \\
\hline 9. & 1 & 1 & 3 & 3 & 1 & 29. & 2 & 1 & 1 & 2 & 2 & 50. & 2 & 3 & 2 & 2 & 2 & 70. & 3 & 2 & 3 & 1 & 1 \\
\hline 10. & 1 & 2 & 1 & 1 & 2 & 30. & 2 & 1 & 1 & 3 & 2 & 51. & 2 & 3 & 2 & 3 & 3 & 71. & 3 & 2 & 3 & 2 & 2 \\
\hline 11. & 1 & 2 & 1 & 2 & 2 & 31. & 2 & 1 & 2 & 1 & 1 & 52. & 2 & 3 & 3 & 1 & 2 & 72. & 3 & 2 & 3 & 3 & 3 \\
\hline 12. & 1 & 2 & 1 & 3 & 2 & 32. & 2 & 1 & 2 & 2 & 2 & 53. & 2 & 3 & 3 & 2 & 2 & 73. & 3 & 3 & 1 & 1 & 3 \\
\hline 13. & 1 & 2 & 2 & 1 & 2 & 33. & 2 & 1 & 2 & 3 & 2 & 54. & 2 & 3 & 3 & 3 & 2 & 74. & 3 & 3 & 1 & 2 & 3 \\
\hline 14. & 1 & 2 & 2 & 2 & 2 & 34. & 2 & 1 & 3 & 1 & 1 & 55. & 3 & 1 & 1 & 1 & 2 & 75. & 3 & 3 & 1 & 3 & 3 \\
\hline 15. & 1 & 2 & 2 & 3 & 2 & 35. & 2 & 1 & 3 & 2 & 1 & 56. & 3 & 1 & 1 & 2 & 3 & 76. & 3 & 3 & 2 & 1 & 3 \\
\hline 16. & 1 & 2 & 3 & 1 & 1 & 36. & 2 & 1 & 3 & 3 & 2 & 57. & 3 & 1 & 1 & 3 & 3 & 77. & 3 & 3 & 2 & 2 & 3 \\
\hline 17. & 1 & 2 & 3 & 2 & 1 & 37. & 2 & 2 & 1 & 1 & 2 & 58. & 3 & 1 & 2 & 1 & 2 & 78. & 3 & 3 & 2 & 3 & 3 \\
\hline 18. & 1 & 2 & 3 & 3 & 2 & 38. & 2 & 2 & 1 & 2 & 2 & 59. & 3 & 1 & 2 & 2 & 2 & 79. & 3 & 3 & 3 & 1 & 2 \\
\hline 19. & 1 & 3 & 1 & 1 & 2 & 39. & 2 & 2 & 1 & 3 & 2 & 60. & 3 & 1 & 2 & 3 & 3 & 80. & 3 & 3 & 3 & 2 & 3 \\
\hline \multirow[t]{2}{*}{20.} & 1 & 3 & 1 & 2 & 3 & 40. & 2 & 2 & 2 & 1 & 2 & 61. & 3 & 1 & 3 & 1 & 1 & 81. & 3 & 3 & 3 & 3 & 3 \\
\hline & & & & & & 41. & 2 & 2 & 2 & 2 & 2 & & & & & & & & & & & & \\
\hline
\end{tabular}

Source: Authors' work

Table 3 shows a printout of eighty-one of the default if-then rules. Four digits in the second and the fifth column of Table 3 indicate the input variables (1. TAX, 2. AMORT, 3. LTIA, 4. PROV), and the digits in the third and the sixth column of Table 3 indicate the output variable (Conservatism Level). Each input variable can assume three values (1-low, 2-medium, and 3-high), and output variables can also get three values (1-aggressive, 2-FAIR and 3-conservative).

By applying rules from Table 3, which have been set on the basis of input data, internal and external users of financial reports can find out if there is bias in financial reports for the year 2015. For example: if TAX - IOW, AMORT - IOW, LTIA - Iow and PROV - low, then Conservatism Level = Aggressive (rule 1); or if TAX - high, AMORT high, LTIA - low and PROV - high, then Conservatism Level = Conservative (rule 75).

Figure 3 and Figure 4 show the areas of knowledge according to input variables TAX and AMORT and Conservativism level variable (vertical axis variable). Because of the visual display, the output variable is a single value (singleton). The functions of the input and the output variables are located above both indicated areas of knowledge. The difference between the two presented areas of knowledge is in the overlap of membership functions, which the researcher himself determines. In the case of the knowledge area shown in Figure 4 there is little overlapping of 
membership functions, and in case of the knowledge area shown in Figure 5 there is the middle overlapping of membership functions. It is crucial that both areas of knowledge confirm theoretical assumptions, i.e., higher levels of TAX and AMORT variables result in a higher level of conservatism.

Figure 3

Illustration area of knowledge for variables TAX, AMORT and Conservatism Level small overlap


Source: Authors' work

Figure 4

Illustration area of knowledge for variables TAX, AMORT and Conservatism Level middle overlap


Source: Authors' work

\section{Practical implications}

International Accounting Standards Board (2016) states in the Conceptual Framework for Financial Reporting that the objective of financial reporting is to provide financial information that is useful to users in making decisions relating to providing resources to the entity. The example of the crisis in the USA related to Enron shows that auditors can be unreliable (Edelman et al. 2011). Kim et al. (2019) investigate the effect of mandatory audit firm rotation and the conclusion is that mandatory audit firm rotation acts as a bonding mechanism to mitigate agency problems, but the problem of bias in financial reporting exists despite rotations of auditors or other institutional solutions.

To conclude, there is a need for a model which could help users of financial reports to prevent issues which affect their interests. The model provided in this paper can be an indicator that there is a need for more detailed studies of entities' financial reports.

The fuzzy logic system can be used through various programmes available even through the open source on the Internet. Alcalá-Fdez et al. (2016) have conducted 
a survey about fuzzy systems software, and their finding is that, in other fields, the Matlab toolbox is widely used in the risk analysis. As the bias in financial reporting is a type of risk analysis, for the purpose of this paper a fuzzy logic system has been made using Matlab, but it can be made using any other software as well. For the practical application of the model, it is necessary to calculate values for each variable in the reporting period so that users could put values of the entity which they are interested in, into the model and determine potential bias in financial reporting.

\section{Conclusions}

The study of the bias in financial reports included 1,060 of the largest Croatian companies. The statistical analysis was carried out using six variables called TAX, AMORT, LTIA, PROV, OCA and OCL, which mostly reflect the effects of applied accounting policies. The theoretical assumption is that a higher or a lower value of a particular variable indicates the aggressiveness or the conservatism of financial statements. Variables TAX, AMORT, PROV, and OCL behave uniformly, i.e., a higher value of these variables indicates conservatism, while a lower value indicates aggressive accounting. The variables LTIA and OCA theoretically have a reverse effect on the model; their higher value indicates aggressiveness, whereas their lower value points to conservative accounting.

The first step of the research was to collect data on the specified variables and to assess the neutral value of a particular variable. For all variables, except the TAX variable, the mean value was determined by comparing the suitability of the statistical environment and the statistical median. For the TAX variable, the mean value was corrected by the income tax rate, which equaled to 20\%, i.e., 0.2 in the observed period in Croatia. The correlation between the variables was calculated, which for this type of statistical analysis had to be extremely low. The results of the correlation between the selected variables confirmed that suitable variables were chosen.

The presented model can serve as a stimulus for more detailed studies of biased elements of financial statements, whereby bias would be presented by high-quality notes to the financial statements. However, there is a broad spectrum of stakeholders that have an interest in knowing to what extent the financial statements of a particular company deviate from the neutral financial statements, but neither do they have an insight into accounting processing nor are they skilled enough to assess the influence of certain accounting procedures on the bias of financial statements. Therefore, the proposed synthetic model for evaluating the level of conservatism or aggressiveness in financial statements may be sufficient to them, but may also be an indicator that there is a need for more detailed studies of elements identified by the model as conservative or aggressive.

The model formed in this paper has certain limitations. Its major limitation is that it is only an indicator of the presence of deviations from the neutral items of financial statements. An additional downside of the model is that it needs to be tested on a larger sample of companies classified based on their activity and under different business conditions in other countries.

The limitations of the model might include certain variables as well, on the basis of which the model was formed. Revaluation can be one of the most important elements in some economic systems and business conditions, but it is also possible that OCA and OCL variables, which were discarded in the formation of the fuzzy logic system in this paper, could be significant in research on a different sample. Certainly, there are other variables that can be examined and interpreted in the 
context of the bias in financial reporting, but these did not represent a considerable influence within the scope of this research and under existing business conditions. The presence of the bias in different business conditions needs to be examined in both Croatian and other world economies and possibly included in the further development of the proposed model.

Therefore, the recommendations for future studies stem from the limitations of the model. First, the model needs to be tested on other economic systems. Furthermore, the model should be tested on a larger sample of companies in the same industry, in order to identify if there are any differences in the obtained results, achieved in the same period and under the same economic and market conditions, and according to the activities. Therefore, the existing variables need to be examined in other economic circumstances, and further work needs to be done to establish whether there are additional variables that should be included in the model. Certainly, due to different tax treatments, and with the tax liability being the main factor of conservatism in financial statements, the influence of revaluation on the model for determining bias needs to be investigated when testing the sample in different economic conditions.

\section{References}

1. Ahmed, A. S., Duellman, S. (2013), "Managerial Overconfidence and Accounting Conservatism", Journal of Accounting Research, Vol. 51, No. 1, pp. 1-30.

2. Ahmed, A. S., Duellman, S. (2007), "Accounting conservatism and board of director characteristics: An empirical analysis", Journal of Accounting and Economics, Vol. 43, No. 2-3, pp. 411-437.

3. Ahmed, A. S., Bilings, K. B., Morton. R. M., Stanford-Harris, M. (2002), "The role of accounting conservatism in mitigating bondholder-shareholder conflicts over dividend policy and in reducing debt costs", The Accounting Review, Vol. 77, No. 4, pp. 867-890.

4. Alcalá-Fdez, J., Alonso, J. M. (2016), "A Survey of Fuzzy Systems Software: Taxonomy, Current Research Trends, and Prospects", IEEE Transactions on Fuzzy Systems, Vol. 24, No. 1, pp. 40-56.

5. André, P., Filip, A., Paugam, L. (2015), "The effect of mandatory IFRS adoption on conditional conservatism in Europe", Journal of Business Finance and Accounting, Vol. 42, No. 3-4, pp. 482-514.

6. Beskese, A., Kahraman, C., Irani, Z. (2004), "Quantification of flexibility in advanced manufacturing systems using fuzzy concept", International Journal of Production Economics, Vol. 89, No. 1, pp. 45-56.

7. Balakrishnan, K., Watts, R. L., Zuo, L. (2016), "The Effect of Accounting Conservatism on Corporate Investment during the Global Financial Crisis", Journal of Business Finance and Accounting, Vol. 43, No. 5-6, pp 513-542.

8. Ball, R., Shivakumar, L. (2005), "Earnings quality in U.K. private firms: Comparative loss recognition timeliness", Journal of Accounting and Economics, Vol. 39, No. 1, pp. 83-128.

9. Barker, R., McGeachin, A. (2015), "An Analysis of Concepts and Evidence on the Question of Whether IFRS Should be Conservative", ABACUS, Vol. 51, No. 2, pp. 169-207.

10. Barker, R., McGeachin, A. (2013), "Why is there inconsistency in accounting for liabilities in IFRS? An analysis of recognition, measurement, estimation and conservatism", Accounting and Business Research, Vol. 43, No. 6, pp. 579-604.

11. Basu, S. (1997), "The conservatism principle and the asymmetric timeliness of earnings", Journal of Accounting and Economics, Vol. 24, No. 1, pp. 3-37.

12. Beatty, A., Liao, S. (2011), "Do delays in expected loss recognition affect banks' willingness to lend?", Journal of Accounting and Economics, Vol. 52, No. 1, pp. 1-20.

13. Beatty, A., Petacchi, R., Zhang, H. (2012), "Hedge commitments and agency costs of debt: Evidence from interest rate protection covenants and accounting conservatism", Review of Accounting Studies, Vol. 17, No. 3, pp. 700-738. 
14. Beaver, W. H., Landsman, W. R., Owen, E. L. (2012), "Asymmetry in Earnings Timeliness and Persistence: A Simultaneous Equations Approach", Review of Accounting Studies, Vol. 17, No. 4, pp. 781-806.

15. Chai, Y., Jia, L., Zhang, Z. (2009), "Mamdani model based adaptive neural fuzzy inference system and its application", International Journal of Computational Intelligence, Vol. 5, No. 1, pp. 22-29.

16. Čičak, J. (2018), "Fair Value of Financial Statement Elements", University of Rijeka, Faculty of Economics and Business, doctoral dissertation.

17. Díaz, B., Morillas, A. (2012), "Some Experiences Applying Fuzzy Logic to Economics", in Seising, R., Sanz Gonzalez, V. (Eds.), Soft Computing in Humanities and Social Sciences, Springer, Berlin, Heidelberg, pp 347-379.

18. Dietrich, J. R., Muller, K. A., Riedl, E. J. (2007), "Asymmetric timeliness tests of accounting conservatism", Review of Accounting Studies, Vol. 12, No. 1, pp. 95-124.

19. Edelman, D., Nicholson, A. (2011), "Arthur Anderson Auditors and Enron: What happened to their Texas CPA licenses?", Journal of Finance and Accountancy, Vol. 8, pp. 1-9.

20. Ettredge, M., Huang, Y., Zhang, W. (2012), "Earnings restatements and differential timeliness of accounting conservatism", Journal of Accounting and Economics, Vol. 53, No. 3, pp. 489-503.

21. Gao, H., Huang, J. (2018), "Employee Firing Costs and Accounting Conservatism: Evidence From Wrongful Discharge Laws", available at SSRN.

22. Garcia Lara, J. M., Garcia Osma, B., Penalva, F. (2016), "Accounting conservatism and firm investment efficiency", Journal of Accounting and Economics, Vol. 61, No. 1, pp. 221238.

23. Garcia Lara, J. M., Garcia Osma, B., Penalva F. (2009), "Accounting conservatism and corporate governance", Review of Accounting Studies, Vol. 14, No. 1, pp. 161-201.

24. Giovanis, E. (2010), "A study of panel logit model and adaptive neuro-fuzzy inference system in the prediction of financial distress periods", World Academy of Science, Engineering and Technology, Vol. 64, pp. 646-652.

25. Givoly, D., Hayn, C. (2000), "The changing time-series properties of earnings, cash flows and accruals: Has financial reporting become more conservative?", Journal of Accounting \& Economics, Vol. 29, No. 3, pp. 287-320.

26. Huijgen, C., Lubberink, M. (2005), "Earnings conservatism, litigation and contracting: The case of cross-listed firms", Journal of Business Finance \& Accounting, Vol. 32m No. 7-8, pp. 1275-1309.

27. International Accounting Standards Board (2016), International Financial Reporting Standards - Red Book, London, IFRS Foundation.

28. Kaur, A., Kaur, A. (2012), "Comparison of Mamdani-Type and Sugeno-Type Fuzzy Inference Systems for Air Conditioning System", International Journal of Soft Computing and Engineering, Vol. 2, No. 2, pp. 323-325.

29. Khan, M., Watts, R. L. (2009), "Estimation and empirical properties of a firm-year measure of accounting conservatism", Journal of Accounting Economics, Vol. 48, No. 2-3, pp. 132150.

30. Kim, S. M., Kim, S. M., Lee, D. H., Yoo, S. W.,(2019), "How Investors Perceive Mandatory Audit Firm Rotation in Korea", Sustainability, Vol. 11, No. 4.

31. Kim, Y., Li, S., Pan, C., Zuo, L. (2013), "The role of accounting conservatism in the equity market: Evidence from seasoned equity offerings", The Accounting Review, Vol. 88, No. 4, pp. 1327-1356.

32. Lee, E., Wang, K., Wang, Q., Zhang, X. (2018), "Unintended Consequences of Economic Interventionism on Accounting Conservatism: A Natural Experiment", available at SSRN.

33. Lee, C. C. (1990), "Fuzzy logic in control systems: fuzzy logic controller. II", IEEE Transactions on systems, man, and cybernetics, Vol. 20, No. 2, pp. 419-435.

34. Lin, J. W., Hwang, M. I., Becker, J. D. (2003), "A fuzzy neural network for assessing the risk of fraudulent financial reporting", Managerial Auditing Journal, Vol. 18, No. 8, pp. 657-665.

35. Nikolaev, V. (2010), "Debt Covenants and Accounting Conservatism", Journal of Accounting Research, Vol. 48, No. 1, pp. 51-89. 
36. Penman, S. H., Zhang, X. J. (2002), "Accounting conservatism and the quality of earnings, and stock returns", The Accounting Review, Vol. 77, No. 2, pp. 237-264.

37. Pratt, J., (2008), Financial Accounting in an Economic Context, John Wiley \& Sons.

38. Qu, X., Zhang, G. (2010), "Measuring the convergence of national accounting standards with international financial reporting standards: The application of fuzzy clustering analysis", The International Journal of Accounting, Vol. 45, No. 3, pp. 334-355.

39. Ruch, G. W., Taylor, G. (2015), "Accounting conservatism: A review of the literature", Journal of Accounting Literature, Vol. 34, pp. 17-38.

40. Solomons, D. (1986), Making Accounting Policy: The quest for credibility in financial reporting, New York, Oxford University Press.

41. Spandagos, C., Ng, T. L. (2018), "Fuzzy model of residential energy decision-making considering behavioral economic concepts", Applied Energy, Vol. 213, pp. 611-625.

42. Tan, L. (2013), "Creditor control rights, state of nature verification, and financial reporting conservatism", Journal of Accounting and Economics, Vol. 55, No. 1, pp. 1-22.

43. Zhang, J. (2008), "The contracting benefits of accounting conservatism to lenders and borrowers", Journal of Accounting and Economics, Vol. 45, No. 1, pp. 27-54.

44. Wang, R. Z., Ó Hogartaigh, C., van Zijl, T. (2009), "A Signaling Theory of Accounting Conservatism", Journal of accounting literature, Vol. 28., pp. 165-203.

45. Wang, C., Xie, F., Xin, X. (2018), "CEO Inside Debt and Accounting Conservatism", Contemporary Accounting Research, Vol. 35, No. 4, pp. 2131-2159.

46. Watts, R. L. (2003a), "Conservatism in Accounting Part I: Explanations and Implications", Accounting Horizons, Vol. 17, No. 3, pp. 207-221.

47. Watts, R. L. (2003b), "Conservatism in Accounting Part II: Evidence and Research Opportunities", Accounting Horizons, Vol. 17, No. 4, pp. 287-301.

\section{About the authors}

Josip Čičak, Ph.D. is a Teaching and Research Assistant at the Faculty of Economics and Business, University of Rijeka, Department of Accounting. He received a Ph.D. in Accounting at the Faculty of Economics and Business in Rijeka with the dissertation thesis "Fair Value of Financial Statement Elements." He is actively engaged in science projects, bilateral cooperation, and national projects. The author can be contacted at josip.cicak@efri.hr.

Davor Vašiček, Ph.D. is a Full Professor at the Faculty of Economics and Business, University of Rijeka, Department of Accounting. At the moment he is a vice-rector for finance at the University of Rijeka. He has been an editor of several Croatian journals in practical accounting, and he holds the position of the chief editor at Tim4pin, a journal in the field of government and non-profit accounting. He is actively engaged in science projects, bilateral cooperation, and national projects. The author can be contacted at davor.vasicek@uniri.hr. 